\title{
Study of hydraulic lime grout injections in different porous media: an experimental study
}

\author{
F. Jorne \& F. M. A. Henriques \\ Department of Civil Engineering, Universidade Nova de Lisboa, \\ Campus da Caparica, Portugal
}

\begin{abstract}
Grout injection is a widely used technique for masonry consolidation of multileaves masonries, aimed at increasing the compactness and to create links between the internal and external leaves that will improve shear, flexural and compressive resistances. The lack of information about the performance of hydraulic lime based grouts as a function of the porous media to be injected enhances the importance of a detailed research on the subject.

Since it is hard to reproduce real masonry and because it is difficult to visualize what is happening inside the porous media being injected by grout, masonry samples were created by filling plexiglass cylinders with a fraction of limestone sands and crushed bricks. These materials are sieved to obtain different grain size distributions to enable the simulation of different permeabilities and internal structures for the masonry. The flow of the grout through the masonry depends on the fresh grout properties, such as stability, water retention and a rheological behaviour. Thus, the evaluation of the performance of the grout as function of porous media is firstly started by checking the intrinsic rheological properties of grout and then by controlling the injectability of masonry by injection tests on cylinders.

Keywords: grout injection technique, multi-leaves masonry, limestone porous media, brick porous media, water absorption coefficient, hydraulic lime grouts, rheological properties, injectability tests.
\end{abstract}

\section{Introduction}

Grout injection has been regarded as a suitable technique to restore the homogeneity, uniformity of strength and continuity of masonry walls. Research 
has been carried out in these last two decades on the effectiveness of the technique [1-5].

In general, the aims of the technique are: (i) to fill large and small voids and cracks increasing the continuity of the masonry and hence its strength, (ii) to fill the gaps between two or more leaves of a wall, when they are badly connected. These aims can only be fulfilled by knowing with a good precision the morphology of the wall section, the composition of the materials constituting the wall in order to avoid chemical or physical incompatibility with the grout, crack distribution and size, percentage and distribution of voids [1, 3]. Therefore, the effectiveness of a repair with grout injection depends not only on the characteristic of the mix, but also on the knowledge of wall type [6]. It is noted that the crack size distribution and moisture content are also important properties in the assessment of injectability [7].

Injectability tests were used to study the penetrability of grouts. Since it is hard to reproduce a real masonry and because it is difficult to visualize what is happening inside the porous media being injected by a grout, reproducible masonry samples of cylindrical shape were created [4-6, 8]. Two materials with different water absorption coefficient were used in order to study the influence of water loss from grout to porous media in grout injectability.

When a good filling and a good bonding of the grout to the masonry original materials are achieved, the load bearing capacity of the structure will significantly improve after the grout is cured [6, 8]. For this reason, the importance of an optimal grout composition from both fresh and hardened states is crucial. In relation to the fresh state, good rheological properties are of prime importance because they enhance a homogeneous filling of the cracks and voids in the masonry to provide a monolithic behaviour after hardening of the grout [9]. Thus, the brittle mechanisms characterized by the out-of-plane detachment of the leaves are minimized.

\section{Materials studied}

\subsection{Field of use and materials selection}

In principle the selection of a binder to be used in grouts for injection should take into account the compatibility with the original materials to be injected. Therefore the present research program used natural hydraulic lime grout, since it presents mechanical, physical and chemical composition closer to the original materials used in historic masonries - which was the objective of the study comparatively with high content cement based grouts [6]. Trying to enhance the performance of the grouts, superplasticizers were also used in an attempt to get advantages on their rheological properties $[6,10]$.

Taking into consideration all these points, several porous media (PM) were tested/injected with the chosen grout in order to understand this influence in grout injectability. 


\subsection{Grout}

\subsubsection{Grout composition}

The used binder was NHL5 hydraulic lime (EN459-1) produced in Portugal by Secil-Martingança; the formulation of the grout is presented in table 1.

Table 1: $\quad$ Grout composition tested.

\begin{tabular}{cccc}
\hline Binder & W/b & SP & \% SP \\
\hline NHL5 & 0,5 & $\begin{array}{c}\text { Glenium Sky 617 } \\
\text { (BASF) }\end{array}$ & 1.2 \\
\hline
\end{tabular}

Grout design involves the study of the behaviour of a suspension in the fresh and in the hardened state. The required performances of grout at the fresh state are: high penetrability, stability of the suspension, and limited or no bleeding [11]. These characteristics may be affected by many parameters, namely the ratio water/binder, the type and percentage of superplasticizer and the mixing procedure. The water/binder ratio (w/b) tested was $50 \%$ in weight (Table 1 ). According to the bibliography and particularly following the recommendations proposed by Valluzzi [6], a minimum value of water/binder $=55 \%$ (in weight) should be used, although in this case only $50 \%$ was used due to the presence of the superplasticizer which causes an increase in the fluidity of the grout [12].

\subsubsection{Grout rheological behaviour}

The grout rheological behaviour is associated to its properties while fresh, and thus, it should be well understood and controlled so that the grout may be pumped and flow correctly inside the PM where it is going to be injected [12]. An important aspect of rheology is the time-dependent properties of grouts, since such properties do not depend only on the shear rate applied to the sample but also on the time for which the fluid has been subjected to shearing [13]. When the suspension is at rest, the particles will start to flocculate into agglomerates (structural build-up), so an increase of shear stress is needed to overcome the yield stress (in order the grout to start flowing) [14]. In fact, the yield stress exhibited by the same grout composition increased by more than five times between $\mathrm{t}=0$ and $\mathrm{t}=120 \mathrm{~min}$ (Table 2). According to Baltazar [12], for the determination of yield stress the grout behaviour can be considered as Bingham fluid, at least during the period studied in this research.

From a practical point of view, yield stress can be associated to the ability of the grout to fill the voids and its ability to flow when a given shear stress is applied. The knowledge of the yield stress enables to understand if a fluid will flow or not, since it represents that threshold. Therefore, the increase of the time causes a reduction of the grout penetrability which suggests that problems can occur during the injection of masonries, if a long temporary stoppage of the injection process occurs.

According to Buckingham Reiner equation [4], the shear stress $(\tau)$ at the wall of the cylindrical channel will be: 


$$
\tau=\frac{\Delta P}{L} \times \frac{D}{4}
$$

where $\mathrm{D}$ is the diameter of the void, $\Delta P$ is the difference of injection pressure in the channel and $L$ the length of the channel. Since the injection pressure is constant, the shear stress at the wall will decrease when the grout penetrates the channel because L, the length filled by grout, is increasing. When shear stress at the wall is lower than the yield stress of grout the flow will stop. This is expressed by the following equation:

$$
\frac{\Delta P}{L} \times \frac{D}{4} \leq \tau O
$$

Knowing that the maximum $L$ of the injection tests is $0.3 \mathrm{~m}$, the pressure adopted in the injection tests ( $\triangle P=1 \mathrm{bar})$ and the yield stress $\tau_{0}$, the minimum void diameter $\left(\mathrm{D}_{\min }\right)$ of the $\mathrm{PM}$ to be injected can be estimated according to eqn. (2). Table 2 presents $D_{\min }$ for each time tested.

Table 2: $\quad \mathrm{D}_{\min }$ of the PM that grout chosen can be injected for different times between the mixture of grout and the injection process.

\begin{tabular}{ccc}
\hline Time (min) & Yield stress $(\mathbf{P a})$ & $\mathbf{D}_{\min }(\mathbf{m m})$ \\
\hline 0 & 0,63 & 0,0075 \\
\hline 30 & 1,17 & 0,0141 \\
\hline 60 & 2,03 & 0,0243 \\
\hline 120 & 3,45 & 0,0414 \\
\hline
\end{tabular}

\subsection{Porous media for injection tests}

Injectability tests were performed to study the penetrability of the grouts. Since it is hard to reproduce a real masonry and it is difficult to visualize what is happening inside the PM being injected, masonry samples were simulated by combining three different crushed limestone sands and three different crushed bricks. Five different grain size media types were adopted to simulate different masonries (Table 3).

Table 3: $\quad$ Different PM studied.

\begin{tabular}{|c|ccc|}
\cline { 2 - 4 } \multicolumn{1}{c|}{} & \multicolumn{3}{|c|}{ Grain size ranges } \\
Media & 0.15-2mm (fine) & 2-4.75mm (media) & 4.75-9.5mm (coarse) \\
\hline A & $1 / 3$ & $1 / 3$ & $1 / 3$ \\
B & $1 / 3$ & - & $2 / 3$ \\
C & $1 / 6$ & - & $5 / 6$ \\
D & - & 1 & - \\
E & - & $1 / 2$ & $1 / 2$ \\
\hline
\end{tabular}


According to Van Rickstal [7] the internal structure of the masonry, the voids volume, the crack size distribution and the moisture content are the most important properties of the masonry with regard to injectability. The total porosity of each PM type was evaluated by measuring the volume of water that could be filled inside each cylinder (Table 4). It is very important to note that this parameter does not give the value of porosity that the grout can penetrate inside the PM, which in fact is much smaller.

In accordance with the survey of the sections of multi-leaves masonry done by certain authors $[14,15]$ some important parameters were adopted to characterize the different PM (Table 4). These parameters are: the voids size average (which correspond to $d_{50}$ - the diameter through which $50 \%$ of the total mass is passing) [4], as well as the parameter $d(90)$ and $d(10)$ (respectively the diameter through which $90 \%$ and $10 \%$ of the total mass is passing).

Table 4: $\quad$ PM characteristics.

\begin{tabular}{|l|cc|cc|ccc|cc|cc|}
\cline { 2 - 11 } \multicolumn{1}{c|}{} & \multicolumn{10}{c|}{ Porous media type } \\
\cline { 2 - 11 } \multicolumn{1}{c|}{} & \multicolumn{1}{c|}{ A } & \multicolumn{1}{c|}{ B } & \multicolumn{2}{c|}{ C } & \multicolumn{2}{c|}{ D } & \multicolumn{2}{c|}{ E } \\
\cline { 2 - 11 } & Stone & Brick & Stone & Brick & Stone & Brick & Stone & Brick & \multicolumn{2}{c|}{ Stone } & Brick \\
\hline Voids size average [mm] & 2.67 & 2.42 & 5.23 & 5.02 & 6.09 & 5.97 & 3.22 & 3.06 & 4.28 & 4.09 \\
d(90) [mm] & 8.17 & 8.22 & 8.97 & 8.82 & 9.00 & 8.97 & 4.58 & 4.50 & 8.62 & 8.59 \\
d(10) [mm] & 0.60 & 0.34 & 0.58 & 0.32 & 1.08 & 0.67 & 2.41 & 2.17 & 2.66 & 2.38 \\
P.M. porosity [\%] & 41.2 & 48.1 & 39.3 & 48.7 & 44.6 & 51.5 & 50.4 & 56.6 & 48.4 & 55.4 \\
WA (\%) & 5.6 & 19.4 & 3.9 & 19.1 & 2.2 & 16.2 & 2.2 & 14.3 & 1.5 & 12.5 \\
\hline
\end{tabular}

To study the water absorption capacity of each PM was calculated the parameter WA (water absorption) using NP EN 1097-6. From Table 4 it was possible to observe the high water absorption capacity of brick PM when compared to the limestone PM. The knowledge of water absorption capacity of the particles of PM is of utmost importance during the injection procedure of grouts. This allows us to have a perception of the quantification of water absorbed by the particles of PM during the injection process, which influences the grout fluidity and consequently the grout injection capacity. The results show that brick PM create more resistance to the flow of grout.

\section{Procedure}

\subsection{Mixing procedures}

The hydraulic lime mixes were prepared at room temperature $22 \pm 1.5^{\circ} \mathrm{C}$ and $53 \%$ of relative humidity. For the preparation of grouts ordinary tap water was used and dry hydraulic lime was hand mixed to ensure a homogeneous distribution before the beginning of the mechanic mixing. The mixing procedure was chosen in accordance with previous research of Baltazar et al. [16]. 


\subsection{Injection tests}

In order to study the grout injection capacity some injectability tests were made. Given the difficulties to reproduce a historical stone masonry due to their high non-homogeneity [6] and to the difficulty of reproducing the characteristics of ancient grouts [15, 17], simplified models were created to analyze the penetration of the grout in the masonry. The models involved the use of transparent Plexiglas cylinders with diameter $152 \mathrm{~mm}$ and height $300 \mathrm{~mm}$, as in ASTM C943. They were filled with one of the media types trying to reproduce as much as possible the real situations.

For injection purposes a device based on previous works [3, 4, 7] was used (Fig. 1). The filled cylinders were injected with the fresh natural hydraulic lime grouts immediately after grout preparation. Injections tests were performed at constant pressure of $1 \mathrm{bar}$, injecting grout in a unidirectional way from bottom to top $[4,6]$.

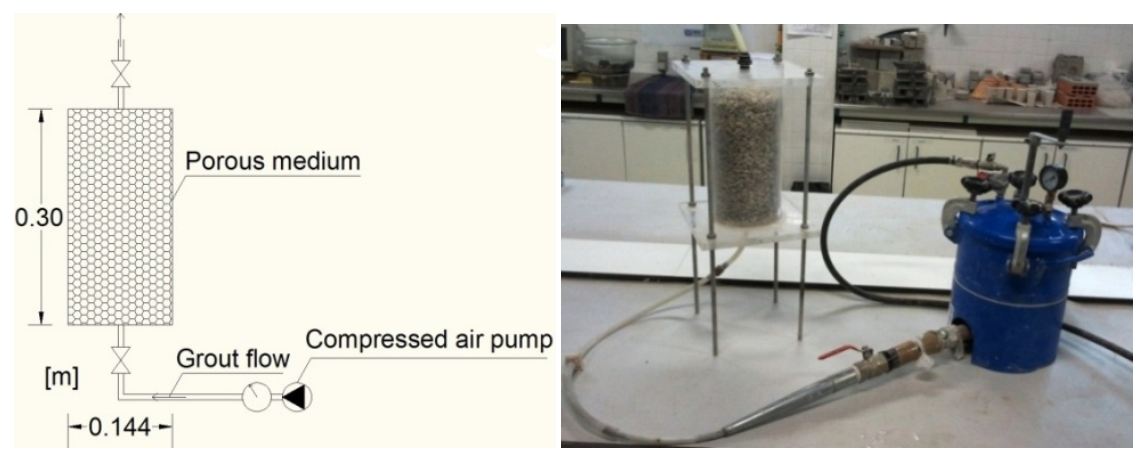

Figure 1: $\quad$ Setup for injection tests used in lab.

\subsection{Injection capacity of the grout}

The goal was to get the injection capacity of the grout as a function of different PM. Each PM is characterized by porosity, grain size distribution and voids size average (Table 4). Since there is no formal quantitative definition for injectability, it can be considered good when the quotient between the volume of grout injected $(\mathrm{m} / \rho)$ and the volume available inside the PM to grout injection $(V v)$ is close to 1 . Thus, it is proposed the following expression for grout Injectability (for a certain injection pressure):

$$
I=\frac{\frac{\mathrm{m}}{\rho}}{V v}
$$

where $I$ is the grout injectability (-), $m$ the injected mass during the injection process $(\mathrm{kg}), \rho$ the density of grout $\left(\mathrm{kg} / \mathrm{m}^{3}\right)$ and $V v$ is the voids volume of PM $\left(\mathrm{m}^{3}\right)$. By measuring the weight of the cylinders before and after injection it was possible to determine (by knowing the density of the grout) the quantity of product injected. Additionally, knowing the amount of voids volume (measured 
by the saturation of water before injection) it was possible to calculate the effective performance of injection in each PM.

\subsubsection{Porous media with different moisture content}

Since it is not expected that masonries are always dry, the media of some cylinders were pre-wetted by simple injection with water (in accordance with experiments of Valluzzi [6], Van Rickstal [7] and Anzani [18]. After the injection of water the valve at the bottom of the cylinder was opened to allow the water to flow out of the sample. Half an hour later the same sample was injected with the hydraulic lime grout. It was noticed that water injection washed out the finer particles, creating major flow channels. Injection tests for the five media types were done with and without pre-wetting of the PM. Through the comparison of injectability values and visual inspections for these two groups it is possible to evaluate the effect of the water content of PM on the injectability of the grout.

\section{Results and discussion}

\subsection{Injection tests}

\subsubsection{Injection capacity: influence of various parameters}

The main objective of this research was the comparison of the performance of selected grout regarding their capacity of penetration and injection in different PM. Injectability (-) was analyzed for two different situations: (i) grout in dry $\mathrm{PM}$ and (ii) grout in pre-wetted PM. From Table 5 is possible to observe that coarser PM (C, D and E) with higher porous media porosity and higher size of finer particles - $d(10)$ (Table 4 ) have values of grout injectability almost 2 times higher than those of the finer PM (A and B). This is observed especially in limestone PM. In what concerns the brick PM, this difference is slighter and PM C shows an intermediate behaviour between fine and coarse PM. Comparing the injectability of PM between these two materials, in general terms it is observed that does not exist a great difference. On the one hand, the crushed brick PM have higher porosity (Table 4) which leads to higher mass/volumes of grout to be injected and have a particle surface with lower roughness which cause a decrease of the resistance to the flow injection. On the other hand, crushed brick PM have a water absorption value significantly higher (Table 3) which provoke an increase of the resistance to the flow injection consequently the grout cannot penetrate in all voids of each PM leaving some voids empty.

From the analysis Table 5 it is possible to observe a close relation with some of the PM characteristics presented in Table 4, namely with parameter $\mathrm{d}(10)$ and porous media porosity. According to Fig. 2, these parameters are the most important of the masonry characterization regarding injectability, independently whether PM is dry or wet at the time of injection. In fact three ranges of values for these parameters can be identified: one for the finer PM A and B, a second for the coarse PM D and E and a third to PM C that lies between the other two ranges (Fig. 3). The same happens with the values of injectability. Thereby the 
considered parameter $\mathrm{d}(10)$ and porous media porosity revealed in general to be adequate for the establishment of an injectability characteristic. The other parameters - voids size average and $d(90)$ - did not reveal appropriate since the correlation with injectability is very low (Fig. 2).

Table 5: $\quad$ Injectability (-) for grout injection in different PM.

\begin{tabular}{|ccc||cc|}
\multirow{2}{*}{ Injectability [-] } & \multicolumn{2}{c||}{ Lime stone } & \multicolumn{2}{c|}{ Crushed Brick } \\
\cline { 2 - 5 } & P.M. Dry & P.M. wetted & P.M. Dry & P.M. wetted \\
\hline A & 0.57 & 0.58 & 0.75 & 0.61 \\
\hline B & 0.54 & 0.48 & 0.71 & 0.46 \\
\hline C & 0.96 & 0.88 & 0.80 & 0.74 \\
\hline D & 0.96 & 0.91 & 0.97 & 0.82 \\
\hline E & 0.97 & 0.92 & 0.89 & 0.84 \\
\hline Average & $\mathbf{0 . 8 0}$ & $\mathbf{0 . 7 5}$ & $\mathbf{0 . 8 2}$ & $\mathbf{0 . 6 9}$ \\
\hline
\end{tabular}

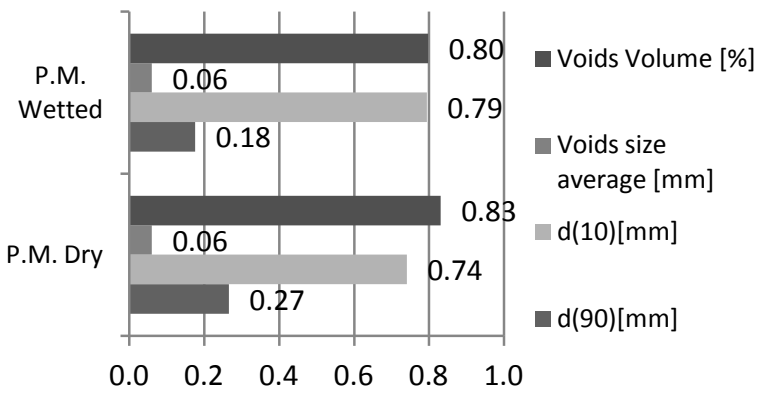

$\mathbf{R}^{2}$ - Correlation with Injectability [-]

Figure 2: Correlation between injectability and PM characteristics (limestone and crushed bricks).

On the analysis of grout injection capacity, normally for a higher value of voids volume is associated a higher value of injectability (Fig. 3). However, this association can only be established if the analysis is for the same material. When the analysis is between different materials, there exist other parameters, as the water absorption capacity, that has a relevant preponderance. Thus, in Fig. 3 is possible to observe that brick PM have a higher porosity. In what concerns to the grout injection capacity, this is similar in both PM. This confirms what was previously written about the water (fluid used to determinate the voids volume) able to penetrate into more voids than grout. The higher the water absorption of PM particles, the higher is the difference between grout volume injected and the voids volume. 

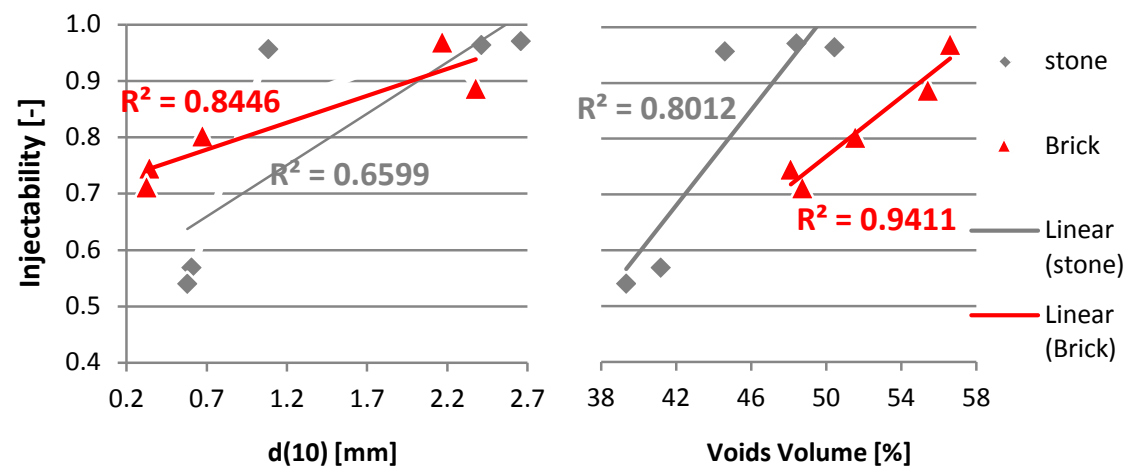

Figure 3: Injectability vs. d(10) ( left picture); injectability vs. voids volume (right picture).

Analysing Table 4 for the PM A and B, the parameter $\mathrm{d}(10)$ which is the diameter through which $10 \%$ of the total $\mathrm{PM}$ is passing is much higher than $\mathrm{D}_{\text {min }}$. However, the variability of shape of channels inside PM (not only cylindrical channel such as it is considered in the model of Buckingham Reiner) could also be a possible explanation to the difficulty that occurs when the grout is injected in these PM. Since $D_{\min }$ is greater in the case of $120 \mathrm{~min}$ due to a high yield stress (Table 2), it is expected that the injection capacity even be lower. Another possible explanation for the non homogeneous filling observed in these PM can be the higher water absorption of these PM (Table 4). The loss of water that occurs in grout leads to an increase of yield stress which means that eqn. (2) may be satisfied - flow will stop in some channels - meaning that grout will try to flow through other available channels, hence the non homogeneous filling.

\subsubsection{Visual inspections during the injection of the cylindrical models}

During the injection test a movie was made to allow the visual analysis of grout penetration inside the cylinder. The following remarks can be made: (a) while injecting the dry material a segregation took place between the water (absorbed by the finer material) and the remaining part of the grout (Fig. 4); (b) when the finer material formed a complete layer through the section of the cylinder, the flow was interrupted (Fig. 4); (c) when an injection blocks, it is not possible to restart the flow by increasing the pressure; $d$ ) when the finer material does not exist or is just present in a small quantities the injection was successful. These results are in accordance with the literature $[4,6,8]$.

The injection of PM A and B was not successful on laboratory, even when PM were wetted. The grout injection did not reach the top of cylinder (Fig. 4a,c) or it was able to advance until reaching the top but leaving part of the voids empty (Fig. 4d), due to the resistance to fill these voids be high. This phenomenon is due to the high quantity of fine particles agglomerated which present a water absorption significantly higher (Table 4) and create more difficulties to the grout be able to penetrate, what hinders the advance of 

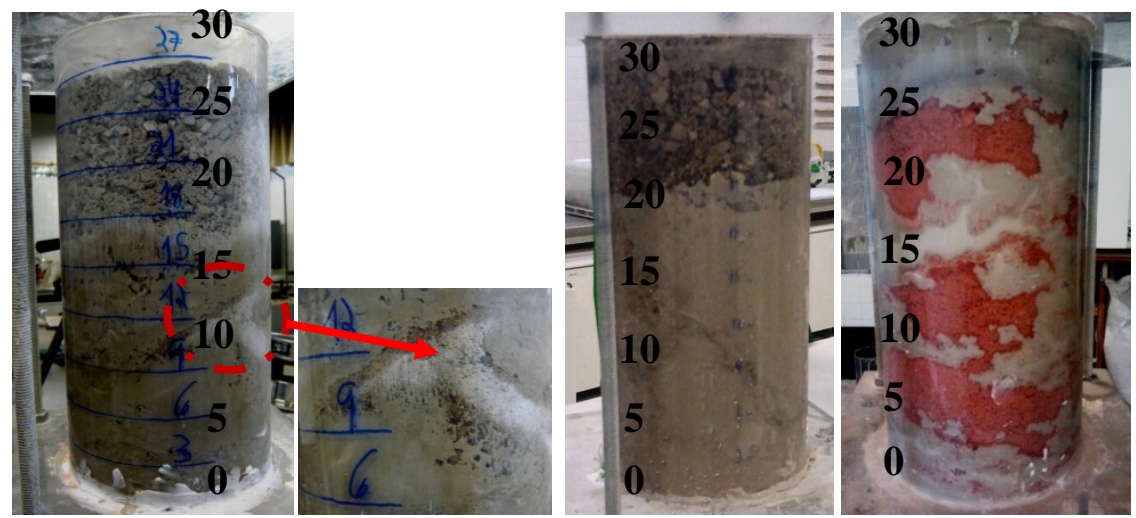

Figure 4: Cylinders filled with media type a) and b) $\mathrm{B}_{\text {stone dry }}$ c) $\mathrm{B}_{\text {,stone wetted, }}$ d) $\mathrm{B}_{\text {,brick dry }}$ being injected.

injection process. From these tests it becomes clear that pre-wetting cannot solve the penetrability issues along with the fact that the mechanical strength of these particular samples will be very poor because there is no absorption of grout inside the finer capilars, since during the pre-wetting, these capilars can absorb water due to the high capillary pressure that is present (Washburn equation [19]). Therefore, pre-wetting has to be used with much precaution, what is in accordance with the literature $[6,7]$.

\section{Conclusions}

The present study allows the following conclusions:

- Given the large variety of masonry types and materials, and in order to better take into account the mentioned difficulties along the article of hydraulic-lime grout to penetrate in extremely fine voids, the importance of evaluating the injectability capacity of a grout for each specific case before intervention was noticed in this work. Similar conclusions were also obtained by the other authors, such as Bras and Henriques [4], Van Rickstal [7] and Kalagri et al. [8].

- The value of injectability for a grout injection in porous media is affected mainly by the parameters: voids volume, quantity of fine particles $-\mathrm{d}(10)$ and water absorption capacity of particles of porous media. Depending on the grain size distribution and the type of material of porous media, the parameters referred have different influence on injectability values. Thus, it is necessary to characterize all parameters for the porous medium in a way that the injection capacity of the grout can be estimated.

- According to the visual inspections during the injection of the cylinders, it was concluded that when there are high amounts (over $33 \mathrm{wt} \%$ ) of the finer material (0.15-2 mm), the reliability of the injection technique is jeopardized [8]. In these cases the grout flow tends to stop during the injection process, enabling an increase of the particle flocculation phenomena [13].This was verified during the 
injection of porous media A and B. Thus, it can be concluded that this grout will not be injectable inside masonry with similar internal characteristics. The visual inspections also showed that pre-wetting of the porous media cannot solve the grout penetrability issues, in addition to a considerable decrease of mechanical strength [7].

- Considering the results obtained, it is possible to conclude that Buckingham Reiner equation is not the best way to check whether a grout is able to penetrate in specific porous media. It seems that the high variability of shape of the channels inside these types of porous media (does not allow to respect the assumptions of the equation) can be a reason for that.

\section{References}

[1] Binda, L., et al. Repair and investigation techniques for stone masonry walls. s.l.: Constr. Build. Mater. 11(3): 133-42, 1997.

[2] Binda, L., Saisi, A. and Tiraboschi, C. Application of sonic tests to the diagnosis of damaged and repaired structures. s.l.: NDT\&E International 34 (2001) 123-138, 2001.

[3] Binda, L., et al. Experimental research for the choice of adequate materials for the reconstruction of the cathedral of Noto. s.l.: Construction and Building Materials 17 (2003) 629-639, 2003.

[4] Bras, Ana and Henriques, Fernando M.A. Natural hydraulic lime based grouts - The selection of grout injection parameters for masonry consolidation. s.l. : Construction and Buiding Materials 26 (2012) 135-144, 2012.

[5] Van Rickstal, Filip, et al. Development of mineral grouts for consolidation injection. s.l.: In Consolidation of Masonry, Ed. D. Van Gemert, Advances in Materials Science and Restoration, 2003, pp. 61-70, 2003.

[6] Valluzzi, M.R. Requirements for the choice of mortar and grouts for consolidation of three-leaf stone masonry walls. s.l.: Paper presented at the workshop repair mortars for historic masonry. Delft University of Technology, Faculty of Civil Engineering and Geosciences, Delft; 26-28 January 2005, 2005.

[7] Van Rickstal, F. Grout injection of masonry, scientific approach and modeling. s.l.: Dissertation. Katholieke Universiteit Leuven; 2000, 2000.

[8] Kalagri, A., Miltiadou-Fezans, A. and Vintzileou, E. Design and evaluation of hydraulic lime grouts for the strengthening of stone masonry historic structures. s.l.: Material and Structures (2010) 43:1135-1146, 2010.

[9] Ignoul, S., Van Rickstal, F. and Van Gemert, D. Application of mineral grouts. Case study and impact on structural behaviour: Church of St. Catharina at Duisburg (B). s.l.: Proceedings International Seminar IV 'Structural Analysis of Historical Constructions', Padua, 10-12 November 2004, Balkema Publ., pp. 719-726, 2004.

[10] Vikan, H. Rheology and reactivity of cementitious binders with plasticizers. s.l.: Doctoral Theses at Norwegian University of Science and Technology, 2005. 
[11] Toumbakari, E.-E., et al. Effect of mixing procedure on injectability of cimentitious grouts. s.l. : Cement and Concrete Research 29 (1999) 867872, 1999.

[12] Baltazar, Luis G., et al. The use of rheology in the study of the composition effects on the fresh behaviour of hydraulic lime grouts for injection of masonry walls. s.l.: Rheol Acta (2013) 52:127-138, 2013.

[13] Bras, Ana, Henriques, Fernando M.A. and Cidade, M.T. Rheological behaviour of hydraulic lime-based grouts. Shear-time and temperature dependence. s.l.: Mech Time-Depend Mater. DOI 10.1007/s11043-0129202-0, 2012.

[14] Bras, A. Grout Optmization for masonry consolidation. s.l.: Phd thesis, Faculdade de Ciências e Tecnologia da Universidade Nova de Lisboa, 2011.

[15] Binda, L. and Anzani, A. Structural behaviour and durability of stone masonry, saving our architectural heritage: the conservation of historic stone structures. s.l.: New York: Wiley, 1997: 112-48, 1997.

[16] Baltazar, L. G., Henriques, F. M. A. and Jorne, F. Optimisation of flow behaviour and stability of superplasticized fresh hydraulic lime grouts through design of experiments. s.l. : Construction and Building Materials, vol. 35, pp. 838-845, Oct. 2012, 2012.

[17] Almeida, C., et al. Phisical characterization and compression tests of one leaf stone masonry walls. s.l.: Construction and Building Materials 30 (2012) 188-197, 2012.

[18] Anzani, A., et al. Use of Sonic and GPR tests to control the effectiveness of grout injections of stone masonry. s.l.: 9th European NDT Conference (ECNDT), September, 25-29, 2006 - Berlin, Germany, 2006.

[19] León y León, Carlos A. New perspectives in mercury porosimetry. s.l.: Advances in Colloid and Interface Science 76-77 (1998) 341-372, 1998. 